\title{
Body mass index, abdominal fatness, weight gain and the risk of psoriasis: a systematic review and dose-response meta-analysis of prospective studies
}

\author{
Dagfinn Aune ${ }^{1,2,3}$ (D) Ingrid Snekvik ${ }^{4,5} \cdot$ Sabrina Schlesinger $^{6} \cdot$ Teresa Norat $^{1} \cdot$ Elio Riboli ${ }^{1} \cdot$ Lars J. Vatten $^{4}$
}

Received: 14 September 2017 / Accepted: 14 February 2018/ Published online: 21 April 2018

(C) The Author(s) 2018

\begin{abstract}
Greater body mass index (BMI) has been associated with increased risk of psoriasis in case-control and cross-sectional studies, however, the evidence from prospective studies has been limited. We conducted a systematic review and doseresponse meta-analysis of different adiposity measures and the risk of psoriasis to provide a more robust summary of the evidence based on data from prospective studies. PubMed and Embase databases were searched for relevant studies up to August 8th 2017. Summary relative risks (RRs) and 95\% confidence intervals (CIs) were calculated using a random effects model. The summary relative risk (RR) for a 5 unit increment in BMI was $1.19\left(95 \% \mathrm{CI} 1.10-1.28, \mathrm{I}^{2}=83 \%, \mathrm{n}=7\right)$. The association appeared to be stronger at higher compared to lower levels of BMI, $p_{\text {nonlinearity }}<0.0001$, and the lowest risk was observed at a BMI around 20. The summary RR was $1.24\left(95 \%\right.$ CI $1.17-1.31, \mathrm{I}^{2}=0 \%, p_{\text {heterogeneity }}=0.72, \mathrm{n}=3$ ) per $10 \mathrm{~cm}$ increase in waist circumference, $1.37\left(95 \%\right.$ CI $\left.1.23-1.53, \mathrm{I}^{2}=0 \%, p_{\text {heterogeneity }}=0.93, \mathrm{n}=3\right)$ per 0.1 unit increase in waist-to-hip ratio, and $1.11\left(95 \%\right.$ CI $\left.1.07-1.16, \mathrm{I}^{2}=47 \%, p_{\text {heterogeneity }}=0.15, \mathrm{n}=3\right)$ per $5 \mathrm{~kg}$ of weight gain. Adiposity as measured by BMI, waist circumference, waist-to-hip ratio, and weight gain is associated with increased risk of psoriasis.
\end{abstract}

Keywords Body mass index · Waist circumference · Waist-to-hip ratio · Weight gain · Psoriasis · Systematic review · Meta-analysis

Electronic supplementary material The online version of this article (https://doi.org/10.1007/s10654-018-0366-z) contains supplementary material, which is available to authorized users.

\section{Dagfinn Aune}

d.aune@imperial.ac.uk

1 Department of Epidemiology and Biostatistics, School of Public Health, Imperial College London, St. Mary's Campus, Norfolk Place, Paddington, London W2 1PG, UK

2 Department of Nutrition, Bjørknes University College, Oslo, Norway

3 Department of Endocrinology, Morbid Obesity and Preventive Medicine, Oslo University Hospital, Oslo, Norway

4 Department of Public Health and Nursing, Faculty of Medicine, Norwegian University of Science and Technology, Trondheim, Norway

5 Department of Dermatology, St. Olavs Hospital, Trondheim University Hospital, Trondheim, Norway

6 German Diabetes Center (DDZ), Institute for Biometrics and Epidemiology, Heinrich Heine University Düsseldorf, Düsseldorf, Germany

\section{Introduction}

Psoriasis is a chronic immune-mediated inflammatory skin disease which is characterized by patches of abnormal skin, which typically are red, itchy and scaly [1]. The condition affects approximately $2 \%$ of the general population, however, the prevalence has doubled over the recent decades in some countries, reaching a lifetime prevalence of $5.8-11 \%$ in Scandinavia [2,3]. A diagnosis of psoriasis has been associated with increased risk of coronary heart disease [4, 5], atrial fibrillation [6], stroke [5-7], thromboembolism [7], certain cancers [8], and possibly other conditions [9-13]. Although several risk factors for psoriasis have been suggested or established including age [14], family history of psoriasis $[15,16]$, skin infections and skin disorders [17], gallstones [18], smoking [19], alcohol consumption [20], and physical inactivity [21, 22], much remains to be learned.

Adiposity is associated with low-grade inflammation through overproduction of inflammatory cytokines. 
Activated macrophages in adipose tissue stimulate adipocytes to secrete TNF- $\alpha$, IL-1, IL-6, and IL- 8 , which may contribute to the development of psoriasis [23, 24]. In addition, higher levels of leptin, an adipokine related to obesity, has also been associated with increased risk of psoriasis [25-27]. A large number of cross-sectional and case-control studies have reported a positive association between adiposity and the risk of psoriasis [28-42]. A meta-analysis from 2012 also suggested a positive association between obesity (BMI of $\geq 30 \mathrm{~kg} / \mathrm{m}^{2}$ ) and psoriasis [43], however, it was largely based on cross-sectional and case-control studies, study designs which can be difficult to rely on for causal inferences because (1) the temporality of the association between the exposure and the disease is not clear in cross-sectional studies, and (2) because casecontrol studies may be hampered by recall and selection biases. However, recently several prospective studies have also reported on the association between body mass index (BMI, $\mathrm{kg} / \mathrm{m}^{2}$ ), abdominal fatness (waist circumference or waist-to-hip ratio) or weight changes and the risk of psoriasis [17, 44-49]. A large study from the UK found a $33 \%$ increase in the risk of psoriasis among obese participants compared to normal weight (BMI of 18.5 to $<25.0 \mathrm{~kg}$ / $\mathrm{m}^{2}$ ) participants [17], while in the Nurses' Health Study I and II there was roughly a doubling in the relative risk among those with grade 2 obesity (BMI of $\geq 35 \mathrm{~kg} / \mathrm{m}^{2}$ ) compared to those with normal weight [44, 45]. Furthermore there was a doubling in the risk among obese participants compared to normal weight participants in the Danish National Birth Cohort [46]. In contrast, a large Korean study only found a weak and non-statistically significant association [48] and a Norwegian study did not find a significant association with overweight or obesity [47], while a second much larger Norwegian study found an almost twofold increase in risk of psoriasis among obese persons [49]. The lower BMI in the Korean population compared to the European and American populations may have contributed to the weaker association in that study. With regard to overweight, the results have been less consistent with three studies reporting statistically significant positive associations [44, 45, 49], while other studies found no clear association [17, 46, 47, 48]. Abdominal fatness (waist circumference and waist-to-hip ratio) is a better predictor of visceral fat than BMI [50], and may be more strongly associated with insulin resistance than BMI [51], however, it is unclear whether waist circumference or waist-to-hip ratio is more strongly associated with psoriasis than BMI. The few studies that investigated the association between waist circumference, waist-to-hip ratio and weight gain were consistent in reporting an increased risk with increasing adiposity [44, 45, 49]. Given the limited number of prospective studies and lack of data on abdominal fatness in previous meta-analyses on adiposity and psoriasis we therefore conducted a systematic review and dose-response meta-analysis of prospective studies to clarify the strength and shape of the dose-response relationship between different measures of adiposity and the risk of psoriasis.

\section{Methods}

\section{Search strategy}

We searched the PubMed and the Embase databases up to August 8th 2017. The search terms used are found in the Supplementary Text. We followed the PRISMA criteria for the reporting of meta-analyses of observational studies [52]. In addition, the reference lists of all the studies that were included in the analysis and the reference list of a published meta-analysis were searched for additional studies [43]. DA and SS conducted the screening of the literature search.

\section{Study selection}

Prospective or retrospective cohort studies, case-cohort studies, or nested case-control studies of the association between measures of body fatness and risk of psoriasis were included. Relative risk (RR) estimates (hazard ratio, risk ratio, odds ratio) had to be available with the $95 \%$ confidence intervals (CIs) in the publication and for the dose-response analysis, a quantitative measure of the exposure and the total number of cases and person-years had to be available in the publication. If there were several publications from the same study we used the study with the largest number of cases, or the study which provided sufficient detail of data to be included in dose-response analyses. A list of the excluded studies and exclusion reasons is found in Supplementary Table 1.

\section{Data extraction}

We extracted from each study: The first author's last name, publication year, country where the study was conducted, the name of the cohort, follow-up period, sample size, sex, age, number of cases, assessment method of anthropometric factors (measured vs. self-reported), type of anthropometric measure, RRs and 95\% CIs, and variables adjusted for in the analysis. Data were extracted by DA and checked for accuracy by SS.

\section{Statistical analysis}

Summary RRs and 95\% CIs for a 5 unit increment in BMI, $5 \mathrm{~kg}$ increase in weight gain, $10 \mathrm{~cm}$ increment in waist 
circumference, and for a 0.1 unit increment in waist-to-hip ratio (consistent with our previous analyses $[53,54]$ ) were estimated using a random effects model [55]. The average of the natural logarithm of the RRs was estimated and the RR from each study was weighted using random effects weights [55]. A two-tailed $p<0.05$ was considered statistically significant.

The method described by Greenland and Longnecker [56] was used for the dose-response analysis and studyspecific slopes (linear trends) and $95 \%$ CIs were computed from the natural logs of the RRs and CIs across categories of adiposity measures. The method requires that the distribution of cases and person-years or non-cases and the RRs with the variance estimates for at least three quantitative exposure categories are known. We estimated the distribution of cases or person-years in studies that did not report these, but reported the total number of cases and person-years [53]. The mean level of BMI, waist circumference, waist-to-hip ratio, and weight gain in each category was assigned to the corresponding relative risk for each study and for studies that reported these measures by ranges, we estimated the midpoint in each category as the average of the lower and upper bounds. For studies which did not use the lowest category as the reference category we converted the risk estimates so that the lowest category became the reference category using the method by Hamling [57]. A potential nonlinear dose-response relationship between BMI, waist circumference, waist-to-hip ratio, weight gain and psoriasis was examined by using fractional polynomial models [58]. We determined the best fitting second order fractional polynomial regression model, defined as the one with the lowest deviance. A likelihood ratio test was used to assess the difference between the nonlinear and linear models to test for nonlinearity [58]. Study quality was assessed using the Newcastle-Ottawa scale which rates studies according to selection, comparability and outcome assessment with a score range from 0 to 9 [59].

Subgroup and meta-regression analyses were conducted to investigate potential sources of heterogeneity including study characteristics such as sex, duration of follow-up, geographic location, number of cases, study quality and adjustment for confounding factors. Heterogeneity between studies was quantitatively assessed by the $\mathrm{Q}$ test and $\mathrm{I}^{2}$ [60]. Small study effects, such as publication bias, were assessed by inspecting the funnel plots for asymmetry and with Egger's test [61] and Begg's test [62], with the results considered to indicate small study effects when $p<0.10$. Sensitivity analyses excluding one study at a time were conducted to clarify whether the results were simply due to one large study or a study with an extreme result.

\section{Results}

We identified 7 prospective studies ( 7 publications) $[17,44-49]$ that were included in the analyses of adiposity and psoriasis risk (Table 1, Fig. 1). Characteristics of the included studies are provided in Table 1. Four studies were from Europe, two studies were from the US, and one study was from Asia (Table 1).

\section{Body mass index}

Seven prospective studies [17, 44-49] were included in the analysis of BMI and psoriasis risk including 17,636 cases and 695471 participants. The summary relative risk (RR) for a 5 unit increment was 1.19 (95\% CI 1.10-1.28, $\left.\mathrm{I}^{2}=83.1 \%, p_{\text {heterogeneity }}<0.0001\right)$ (Fig. 2a). There was no evidence of publication bias with Egger's test, $p=0.12$, or Begg's test, $p=0.37$ (Supplementary Fig. 1). In sensitivity analyses, the summary RR ranged from 1.16 (95\% CI 1.08-1.25) when excluding the Nurses' Health Study II [44] to 1.22 (95\% CI 1.14-1.30) when excluding the Korea National Health Insurance Corporation study [48]. The summary RR was 1.25 (95\% CI $1.19-1.31, \mathrm{I}^{2}=1 \%$, $\mathrm{n}=5$ ) for women and 1.34 (95\% CI 1.11-1.62, $\mathrm{I}^{2}=35 \%$, $\mathrm{n}=2$ ) for men (Supplementary Table 2). There was evidence of a nonlinear association between BMI and psoriasis, $p_{\text {nonlinearity }}<0.0001$, and there was a steeper increase in risk at higher compared to lower levels of BMI, however, some evidence of increased risk was observed even within the normal BMI range and the lowest risk was observed with a BMI between 16.75 and 20 (Fig. 2b, Supplementary Table 3).

\section{Waist circumference}

Three cohort studies [44, 45, 49] were included in the analysis of waist circumference and psoriasis risk and included 2068 cases among 179411 participants. The summary RR was $1.24\left(95 \%\right.$ CI $1.17-1.31, \mathrm{I}^{2}=0 \%$, $\left.p_{\text {heterogeneity }}=0.72\right)$ per $10 \mathrm{~cm}$ increase in waist circumference (Fig. 3a). The summary RR was 1.22 (95\% CI $\left.1.15-1.30, \mathrm{I}^{2}=0 \%, \mathrm{n}=3\right)$ for women and $1.44(95 \% \mathrm{CI}$ $1.23-1.66, \mathrm{n}=1$ ) for men. There was no evidence of a nonlinear association between waist circumference and psoriasis risk, $p_{\text {nonlinearity }}=0.09$ (Fig. $3 \mathrm{~b}$, Supplementary Table 4).

\section{Waist-to-hip ratio}

Three cohort studies [44, 45, 49] were included in the analysis of waist-to-hip ratio and psoriasis risk and included 2068 cases among 179411 participants. The summary 


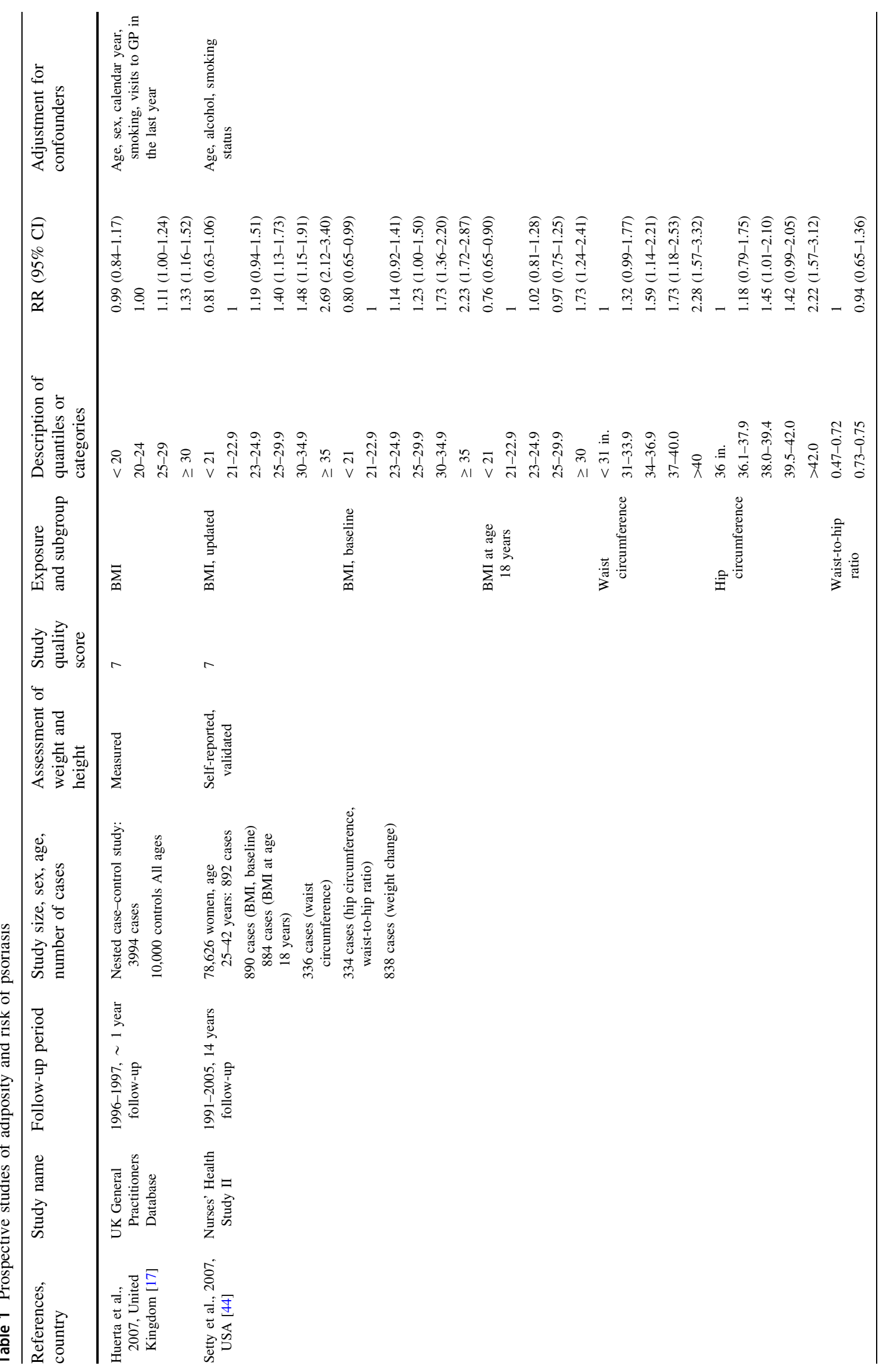




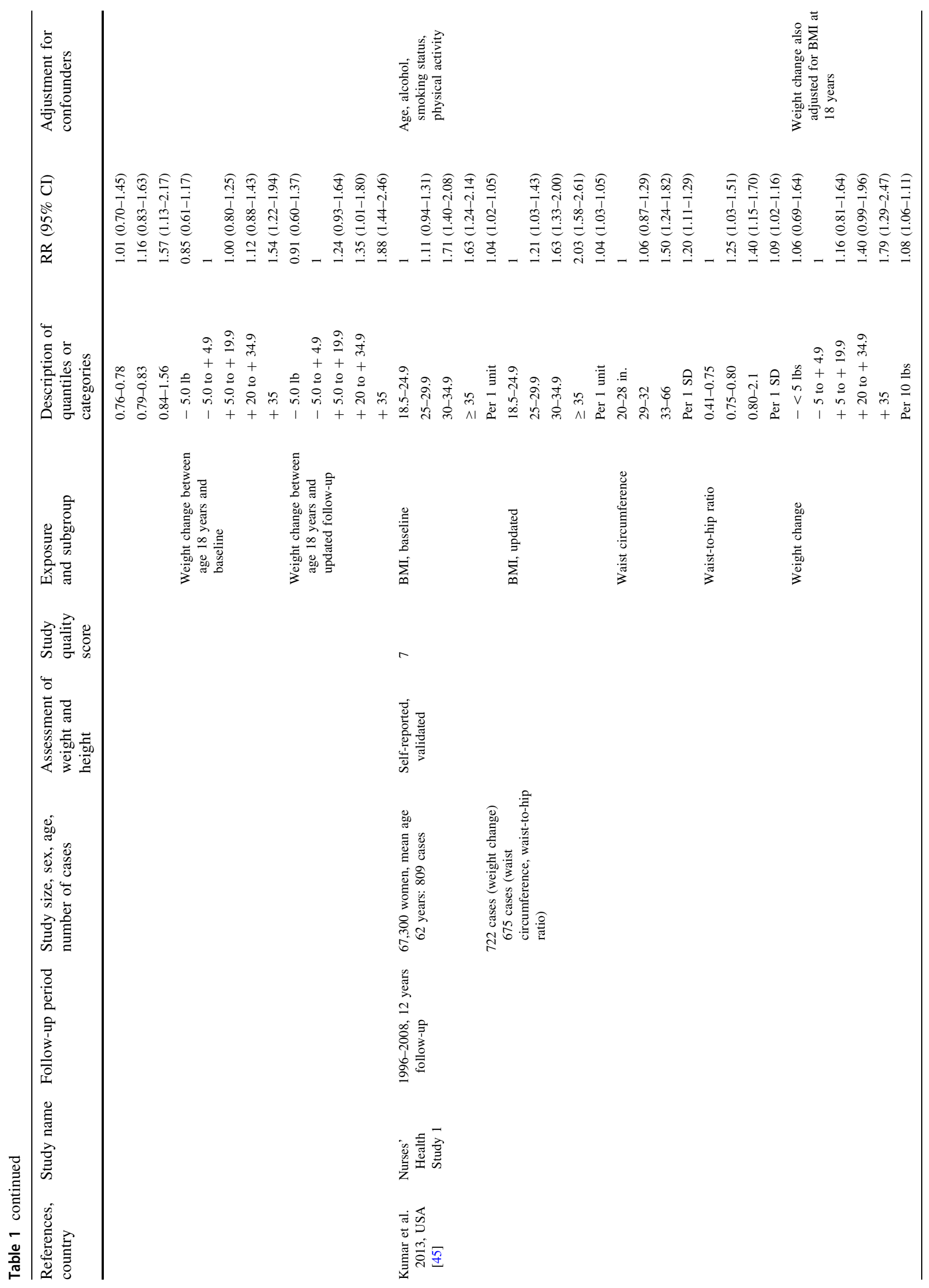




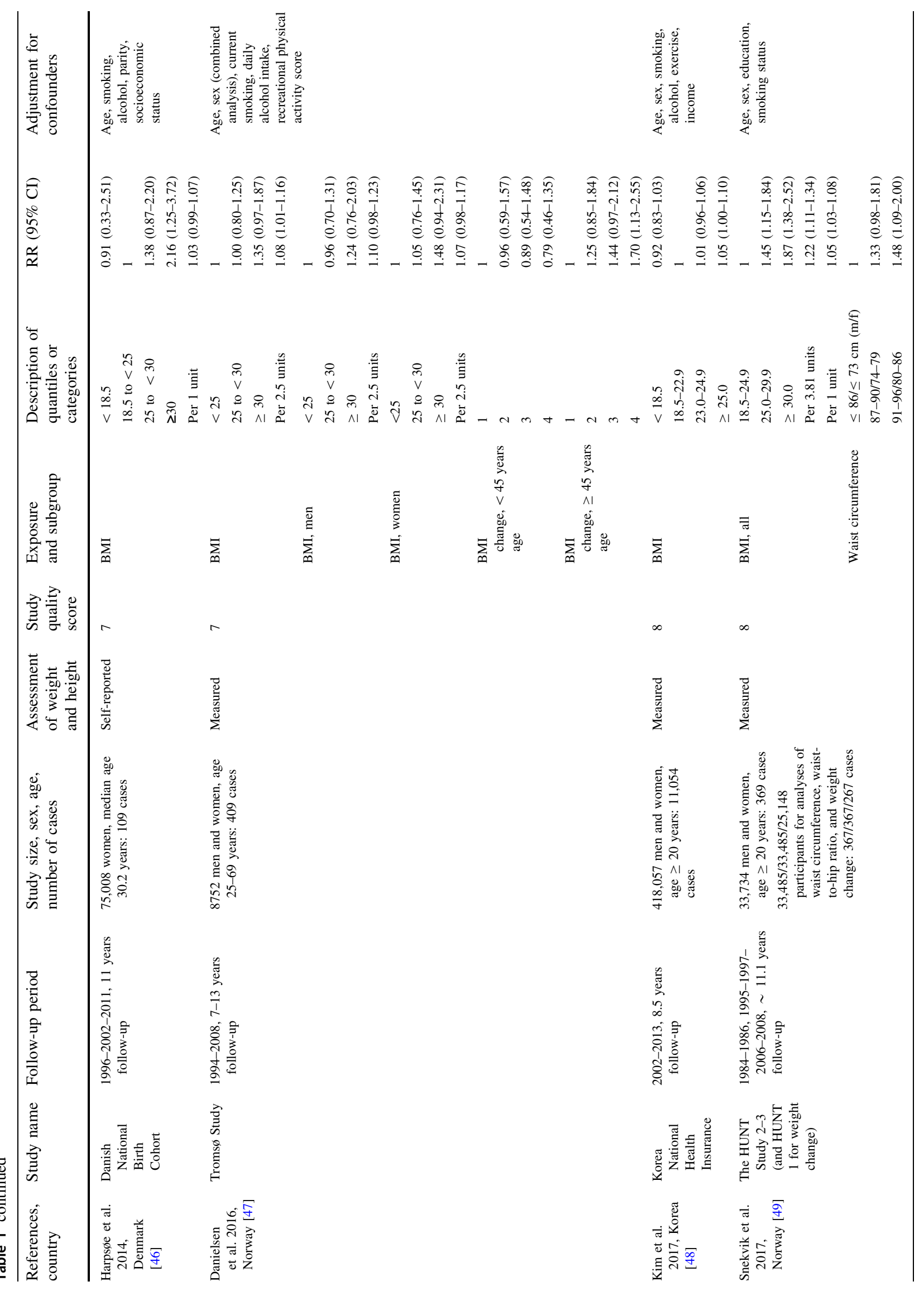




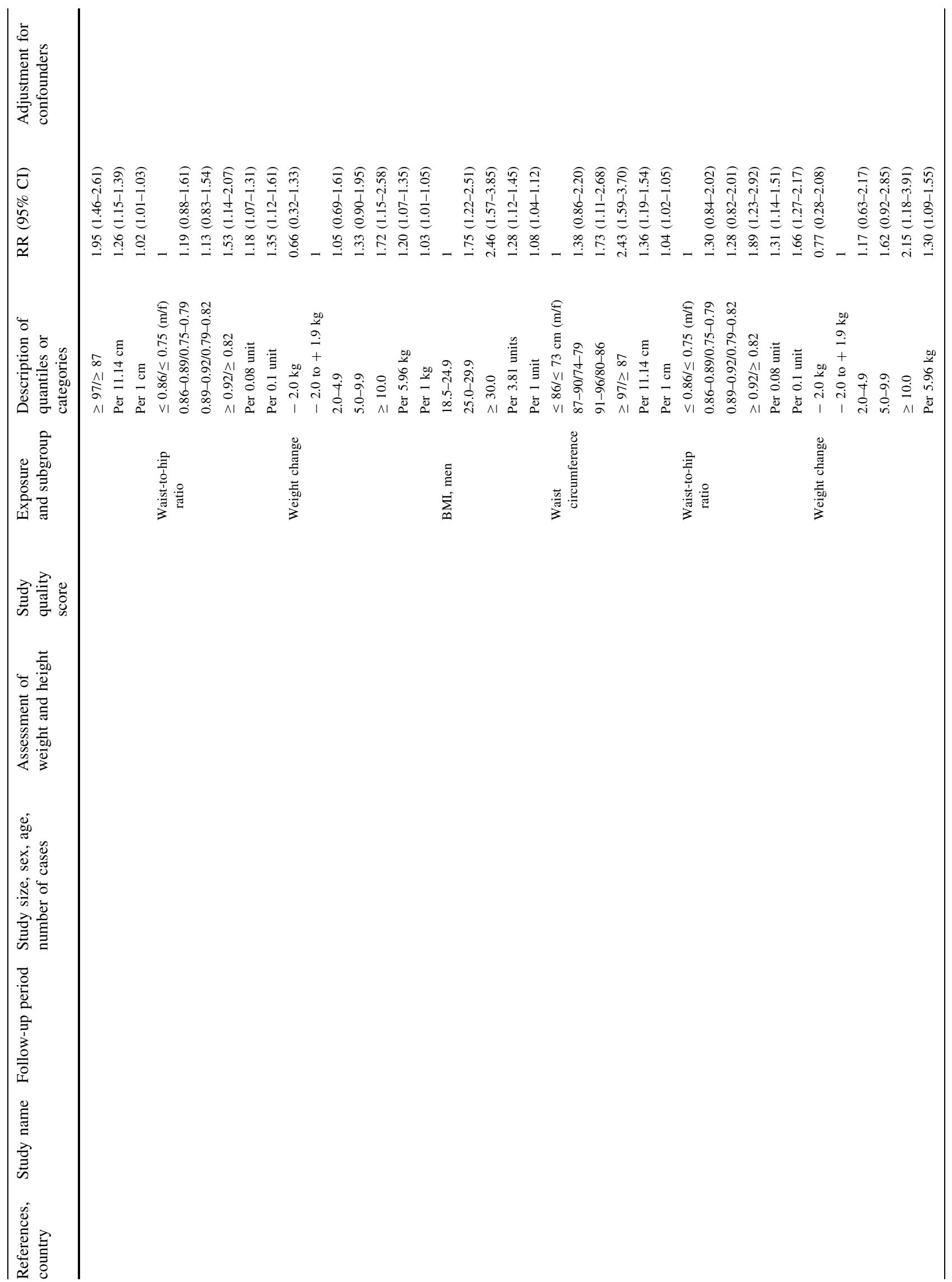




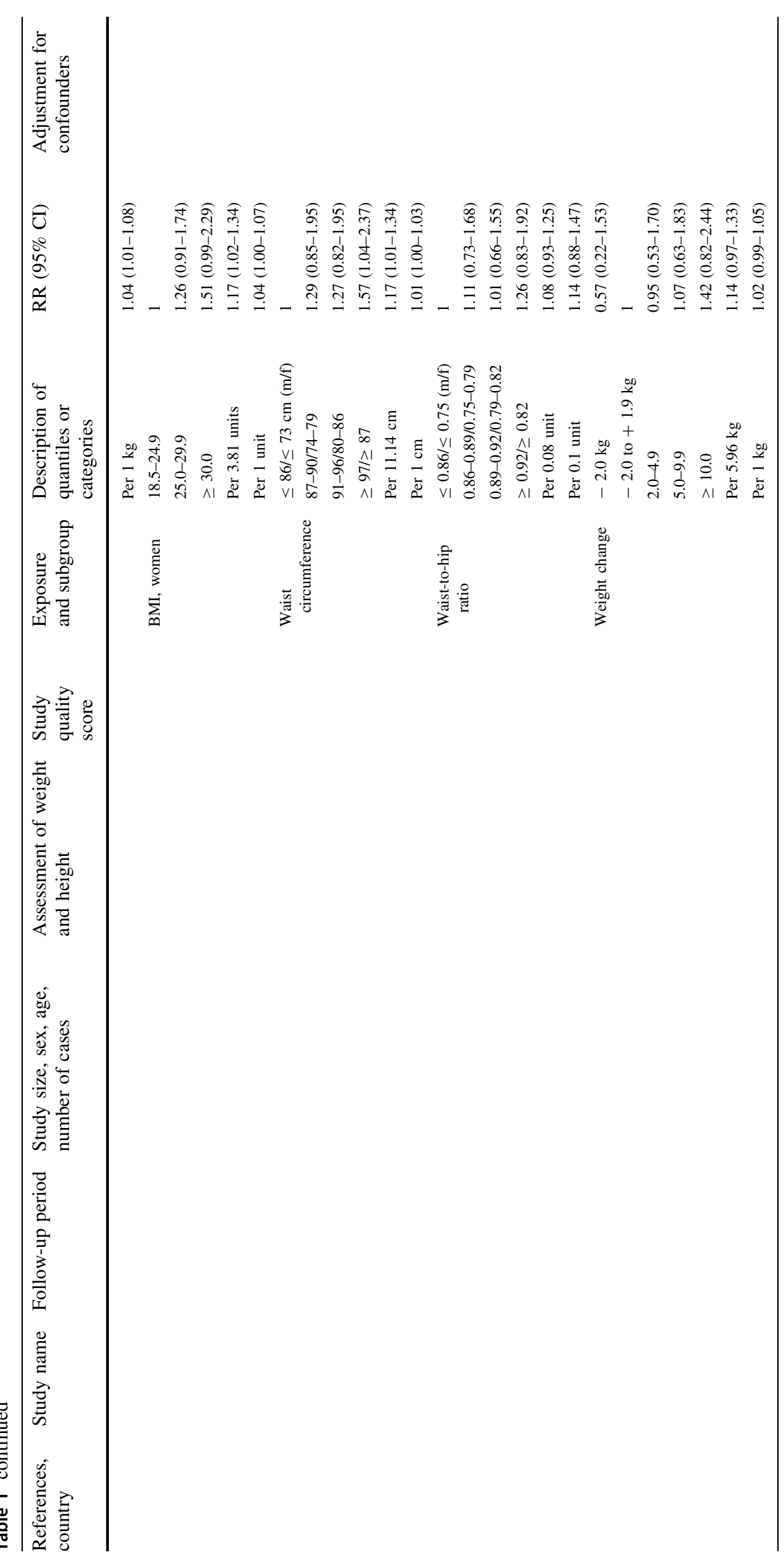




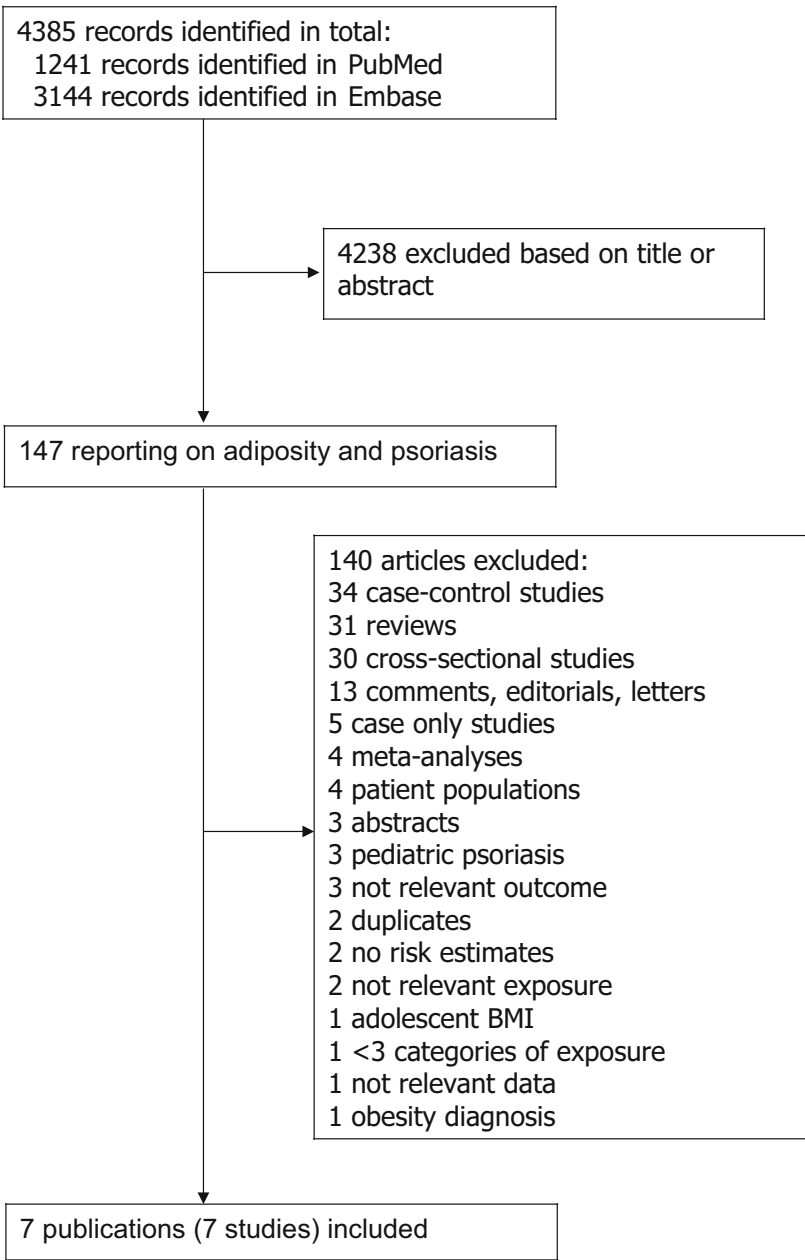

Fig. 1 Flow-chart of study selection

$\mathrm{RR}$ for a 0.1 unit increment in waist-to-hip ratio was 1.37 $\left(95 \%\right.$ CI $\left.1.23-1.53, \mathrm{I}^{2}=0 \%, p_{\text {heterogeneity }}=0.93\right)$ per 0.1 unit increase in waist-to-hip ratio (Fig. 4a). The summary RR was $1.32\left(95 \%\right.$ CI $\left.1.17-1.49, \mathrm{I}^{2}=0 \%, \mathrm{n}=3\right)$ for women and $1.31(95 \%$ CI $1.14-1.51, \mathrm{n}=1)$ for men. There was no evidence of a nonlinear association between waist-to-hip ratio and psoriasis risk, $p_{\text {nonlinearity }}=0.59$ (Fig. 4b, Supplementary Table 5).

\section{Weight changes}

Three cohort studies [44, 45, 49] were included in the analysis of weight changes (between age 18-20 and baseline in the Nurses' Health Studies I and II and between baseline of HUNT 1 and baseline of HUNT 2) and psoriasis risk and included 1968 cases among 171074 participants. The summary RR per $5 \mathrm{~kg}$ of weight gain was 1.11 (95\% CI $1.07-1.16, \mathrm{I}^{2}=46.8 \%, p=0.15$ ) (Fig. 5a). The summary RR was $1.10\left(95 \%\right.$ CI $1.07-1.14, \mathrm{I}^{2}=19 \%, \mathrm{n}=3$ ) for women and 1.27 (95\% CI 1.08-1.48, $\mathrm{n}=1$ ) for men. There was no evidence of a nonlinear association between weight gain and psoriasis risk, $p_{\text {nonlinearity }}=0.26$ (Fig. $5 \mathrm{~b}$, Supplementary Table 6). It was not possible to conduct dose-response analyses of weight loss as all studies only reported risk estimates for one category of weight loss, however, the summary RR comparing weight loss with stable weight was $0.89\left(95 \%\right.$ CI $0.69-1.13, \mathrm{I}^{2}=0 \%$, $p=0.50)$.

\section{Subgroup analyses and study quality}

In subgroup analyses, there was little evidence of heterogeneity between subgroups when stratified by sex, geographic location, number of cases, and adjustment for confounding factors including age, smoking, alcohol, and physical activity ( $p_{\text {heterogeneity }} \geq 0.07$ for all comparisons). There was some evidence of heterogeneity when studies were stratified by duration of follow-up, $p_{\text {heterogene- }}$ ity $=0.03$, with a stronger association among studies with a longer duration of follow-up compared to a shorter duration of follow-up ( $\geq 10$ vs. $<10$ years follow-up).

The mean (median) study quality scores were 7.3 (7.0) out of 9 possible points for the seven studies included in the dose-response analysis of BMI and psoriasis and five studies had a score of 7 and two studies had a score of 8 points (Table 1).

\section{Discussion}

In this meta-analysis of prospective studies we found evidence of an increased risk of psoriasis with higher BMI, waist circumference, waist-to-hip ratio, and weight gain. There was a $19,24,37$, and $11 \%$ increase in the relative risk of psoriasis for each 5 unit increment in BMI, $10 \mathrm{~cm}$ increase in waist circumference, 0.1 unit increment in waist-to-hip ratio and $5 \mathrm{~kg}$ of weight gain, respectively. Although there was some evidence of nonlinearity of the association between BMI and psoriasis, there was a clear dose-response relationship, with the lowest risk observed around a BMI of 20 , and with a significant increase from a BMI around 22.5-24, and risk increased exponentially with increasing BMI. The associations between waist circumference, waist-to-hip ratio, and weight gain and psoriasis appeared to be linear. The findings are consistent with a previous meta-analysis of cross-sectional and case-control studies which found an increased risk with obesity [43], however, to our knowledge this is the first meta-analysis of only prospective studies to find an increased risk, and the first meta-analysis to investigate the dose-response relationship between different measures of adiposity such as abdominal adiposity and weight gain and psoriasis risk. The previous meta-analysis reported a $66 \%$ increase in the relative risk among obese subjects compared to normal 
Fig. 2 BMI and psoriasis

Study

Kim, 2017

Snekvik, 2017

Danielsen, 2016

Harpsøe, 2014

Kumar, 2013

Huerta, 2007

Setty, 2007

Overall
Relative Risk

(95\% Cl)

$1.05(1.00,1.10)$

$1.30(1.15,1.47)$

$1.10(0.96,1.26)$

$1.39(1.10,1.75)$

$1.21(1.13,1.30)$

$1.12(1.05,1.19)$

$1.31(1.21,1.42)$

$1.19(1.10,1.28)$

\begin{tabular}{|c|c|c|c|c|c|}
\hline$T$ & $T$ & & 1 & 1 & $T$ \\
\hline .5 & .75 & 1 & 1.5 & 2 & 3 \\
\hline
\end{tabular}

B Body mass index and psoriasis, nonlinear dose-response analysis

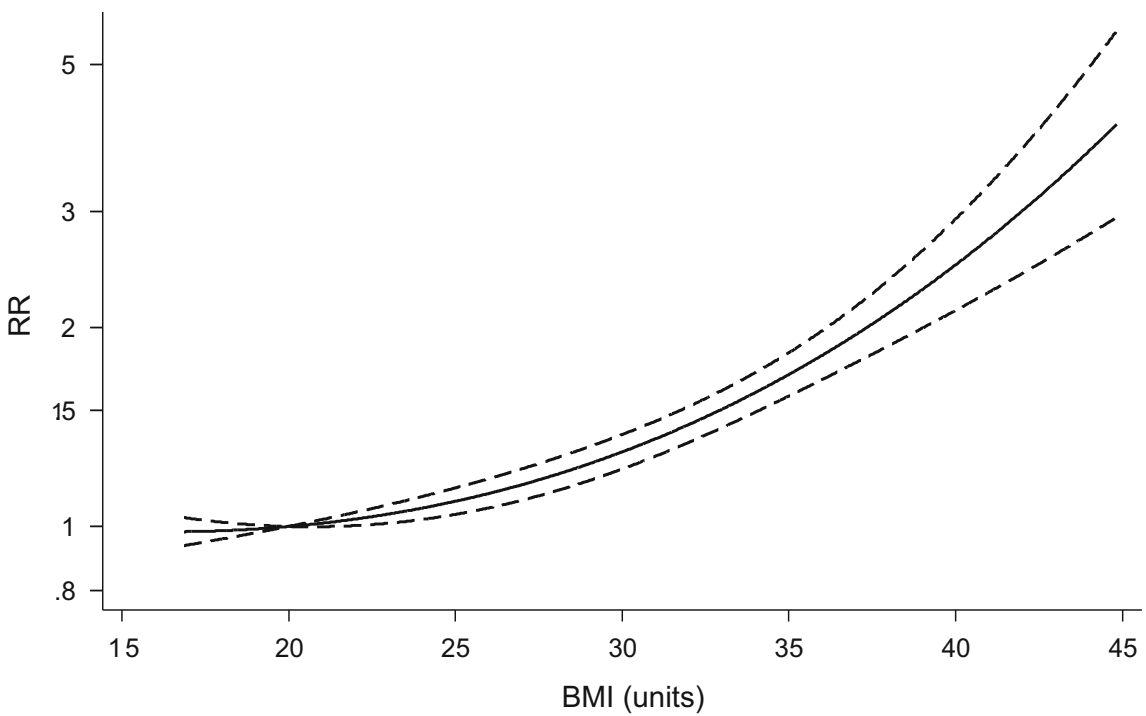

Best fitting fractional polynomial 95\% confidence interval

weight subjects [43], while we found a 2-4 fold increase in the risk of psoriasis among those at the high end of each adiposity measure compared to those who were slim.

Several potential mechanisms may explain an association between greater adiposity and increased psoriasis risk.
Adiposity is associated with chronic, low-grade inflammation through overproduction of inflammatory cytokines. Activated macrophages in adipose tissue stimulate adipocytes to secrete inflammatory mediators such as TNF- $\alpha$, IL1, IL-6, and IL-8 which may account for some of the 
Fig. 3 Waist circumference and psoriasis
A Waist circumference and psoriasis, linear dose-response analysis, per $10 \mathrm{~cm}$

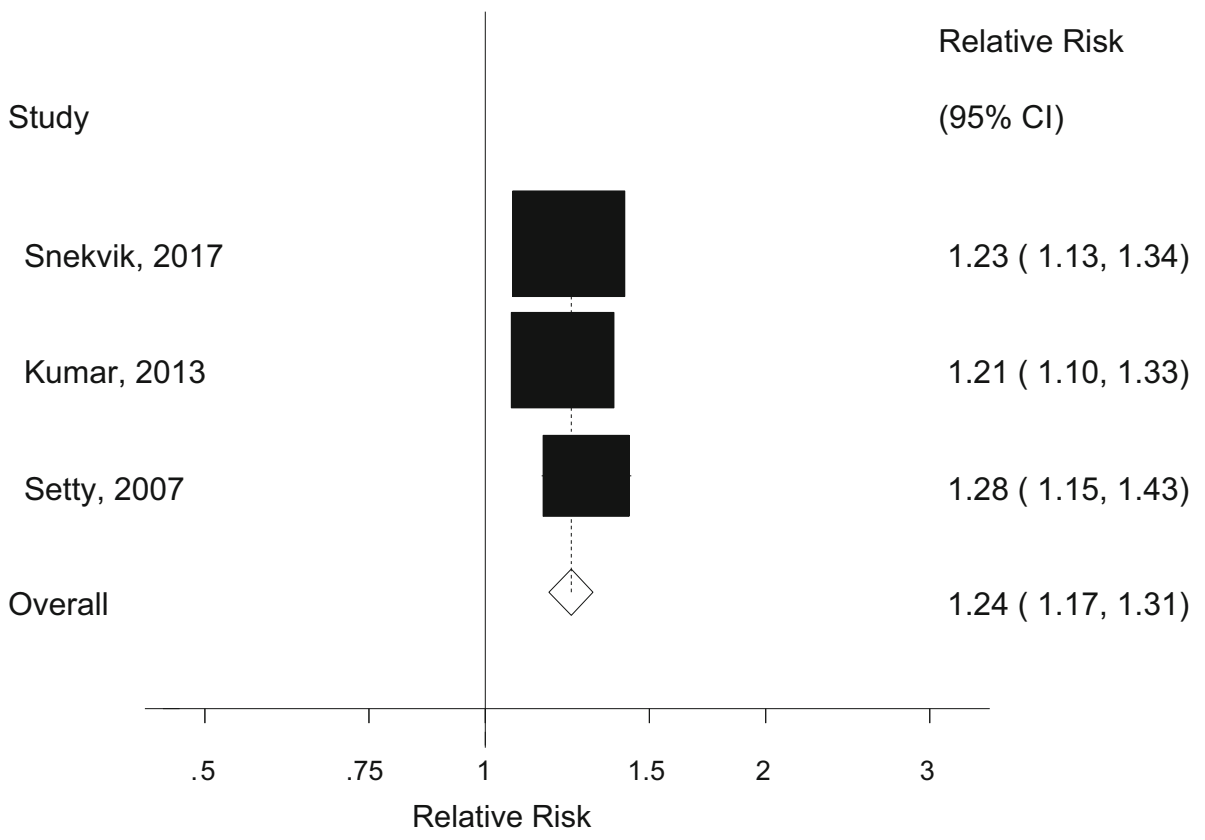

B Waist circumference and psoriasis, nonlinear dose-response analysis

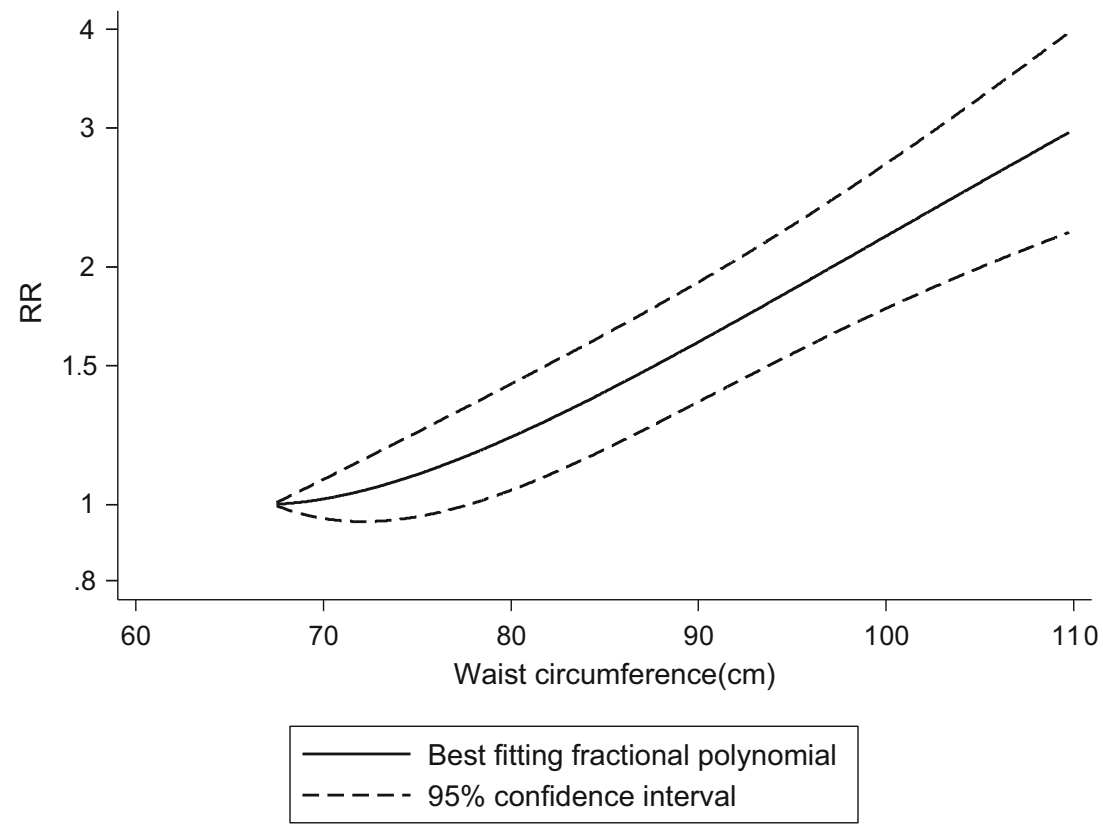

pathologic changes observed in psoriasis patients [23, 24]. Studies in psoriasis patients have also found higher levels of leptin [25-27], an adipokine that is positively correlated to obesity. In addition a positive correlation between leptin and the severity of psoriasis has been observed [25], while lower levels of adiponectin [27, 63] have been found among psoriasis patients. Leptin deficiency has been shown to counteract psoriasis-like skin inflammation in a mouse model, while leptin stimulation of human kerotinocytes has shown to increase the proliferation and to induce secretion of several pro-inflammatory proteins, two of the characteristics of psoriasis [64]. Further support for an important role of obesity in the etiology of psoriasis comes from the observation that weight loss induced by diet and lifestyle 
Fig. 4 Waist-to-hip ratio and psoriasis
A Waist-to-hip ratio and psoriasis, linear dose-response analysis, per 0.1 unit

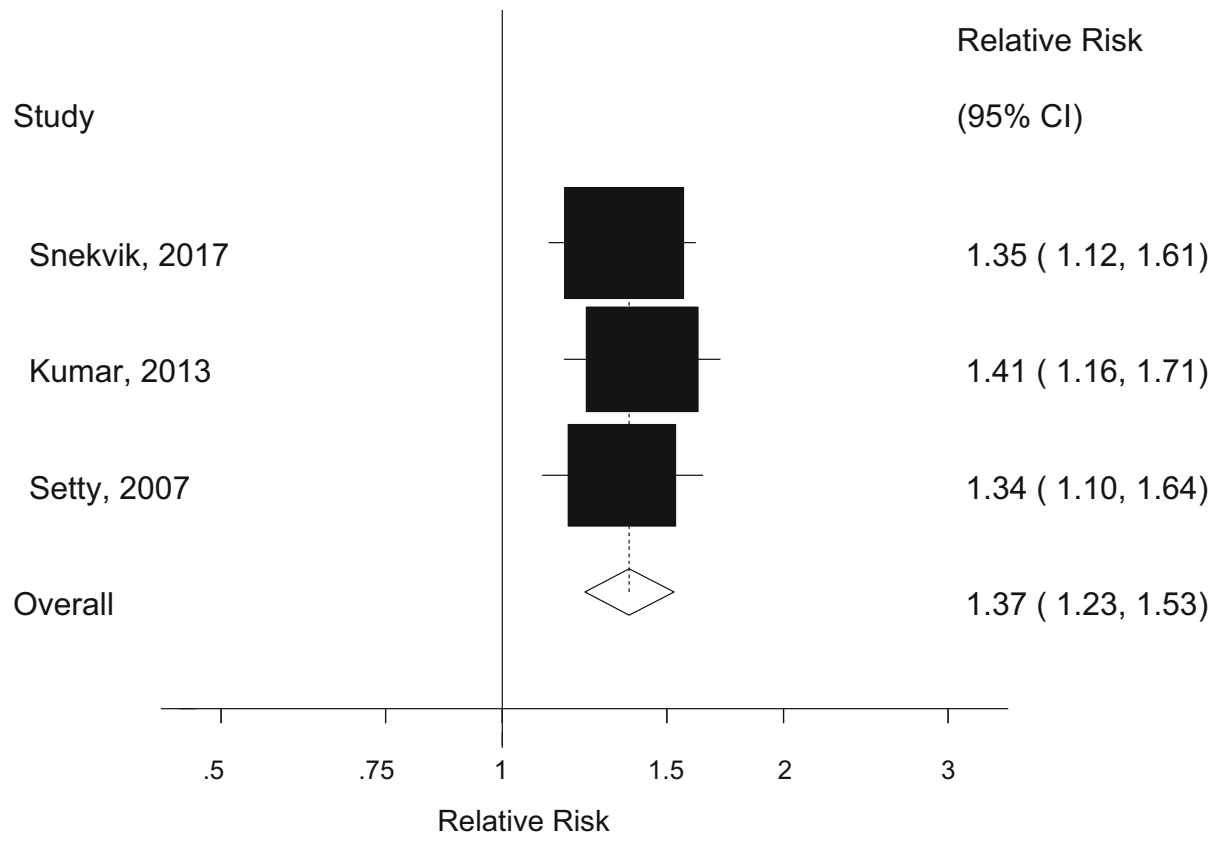

B Waist-to-hip ratio and psoriasis, nonlinear dose-response analysis

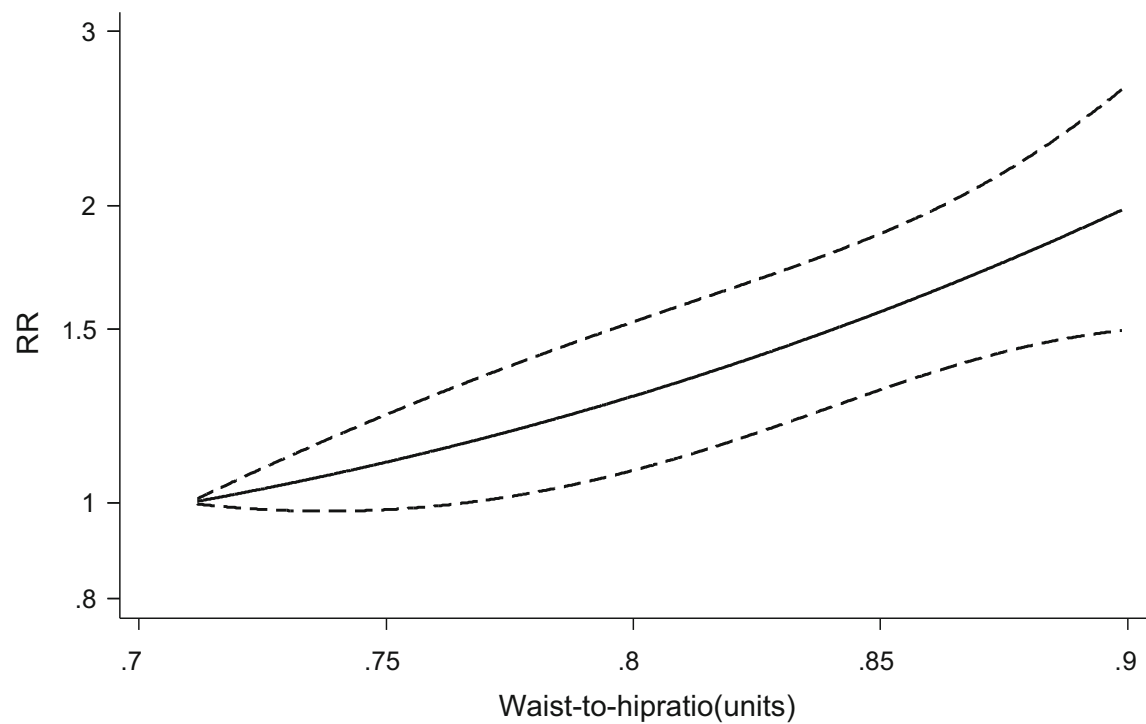

Best fitting fractional polynomial

- - - - 95\% confidence interval changes or obesity surgery in obese psoriasis patients has been found to lead to improvement or remission of the condition over time [65-74]. A diet and exercise intervention was also found to reduce concentrations of TNF- $\alpha$, IL-6, IL-8, C-reactive protein and monocyte chemoattractant protein 1 [75], which may contribute to improvement of psoriasis. Although we did not find a significant association between weight loss and reduced psoriasis risk in the current analysis, we were not able to conduct doseresponse analyses of weight loss and psoriasis risk because the data were reported in only two categories. In addition, the weight loss analysis was based on the total population 
Fig. 5 Weight gain and psoriasis

\section{A Weight gain and psoriasis, linear dose-response analysis, per $5 \mathbf{~ k g}$}

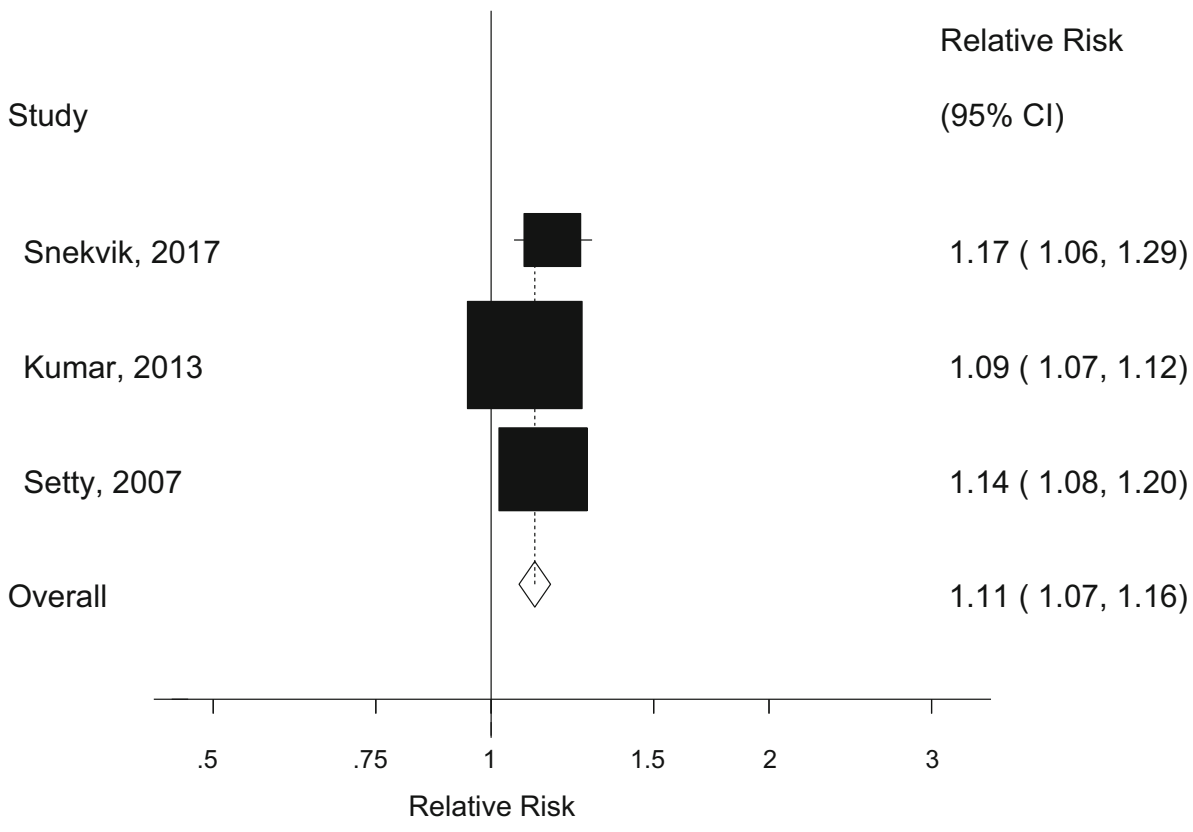

B Weight gain and psoriasis, nonlinear dose-response analysis

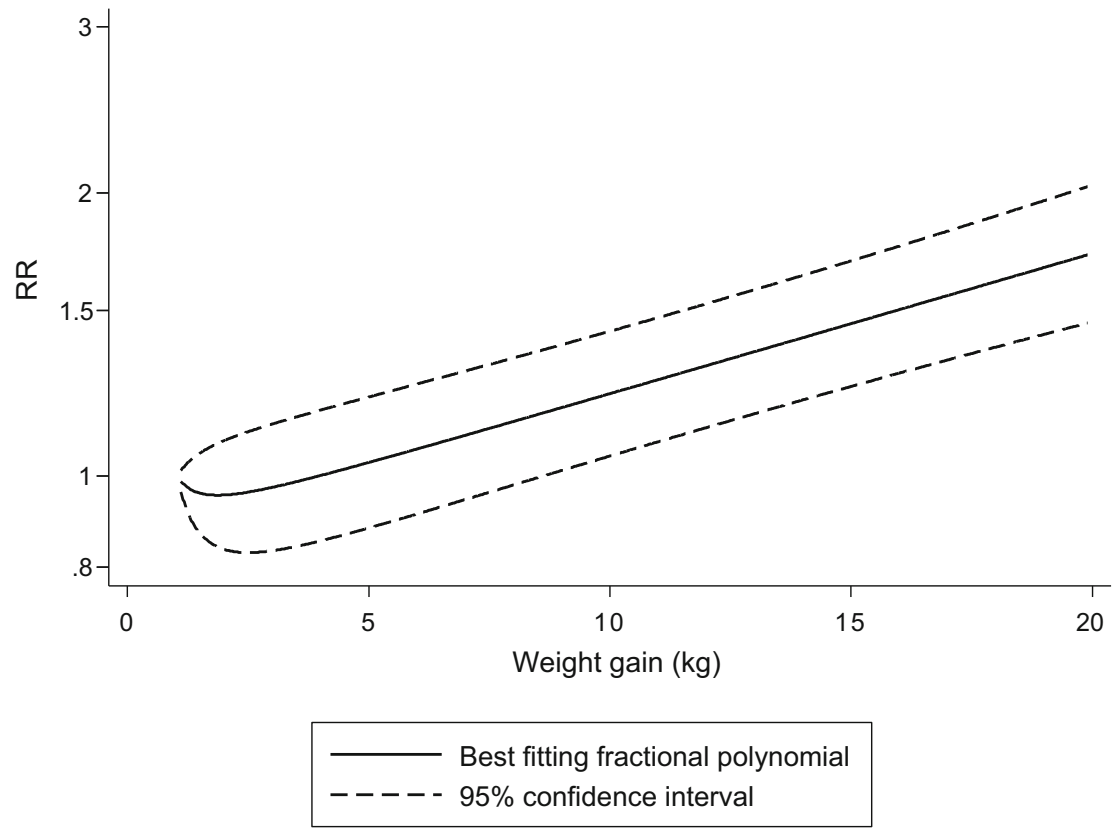

(including those who were normal weight at baseline) so more pronounced associations may have been observed if those analyses had been restricted to those who were overweight and/or obese at baseline.

Our meta-analysis has some limitations which may affect the interpretation of the results. The main limitation is the low number of prospective studies available reporting on waist circumference, waist-to-hip ratio, and weight gain which limited our possibility to conduct subgroup analyses and test for publication bias for these measures and only one study reported on hip circumference. Although it is possible that confounding may have affected the results as overweight and obese persons usually are less physically active and have unhealthier diets than normal weight persons, it is unlikely that such confounding could entirely explain the association because the risk associated 
with body fatness is much stronger than those observed for both physical activity [21] and dietary factors [28]. In addition, the results persisted in subgroup analyses by adjustment for confounding factors and there was little evidence of heterogeneity between these subgroups. Nevertheless, the possibility that unidentified risk factors could confound the associations cannot be entirely excluded. There was some evidence of heterogeneity in the subgroup analysis stratified by duration of follow-up, with a stronger association among studies with a longer duration of followup compared to a shorter follow-up. It is possible that this to some degree also could reflect weight gain over time as we found a positive association between weight gain and psoriasis and because most of the studies only used the baseline assessment for the analysis of BMI and psoriasis. Two studies also found a stronger association between updated BMI and psoriasis than with baseline BMI [44, 45], which also might suggest that weight gain over time could have led to the observed stronger association among studies with longer follow-up.

Measurement errors in the assessment of height and weight may have influenced our results. Although most of the studies relied on self-reported height and weight, there is generally a high correlation between self-reported and measured height and weight and waist and hip circumferences [76, 77]. In addition, the results were similar when studies were stratified by whether the anthropometric measurements were measured or self-reported. Although meta-analyses of published literature may be susceptible to publication bias, we found no evidence of publication bias with either Egger's test or with Begg's test or when visually inspecting the funnel plots, however, we may have had limited power to detect such bias because of the moderate number of studies, and we were not able to reliably test for publication bias in the analyses of waist circumference, waist-to-hip ratio and weight changes.

The assessment of psoriasis diagnoses was based on self-report or validated self-report [44, 45, 47, 49] in some studies and through linkages to medical records or registries in the remaining studies [17, 46, 48], however, several of these studies validated the self-reported diagnoses and found relatively high positive predictive values of between $78 \%$ [3], 82\% [17] and 92\% [45]. While some cases of psoriasis may go undiagnosed, any misclassification of the outcome would tend to attenuate the observed risk estimates because of the prospective nature of the included studies.

Our meta-analysis also has several strengths. Because we based our analysis on prospective studies ambiguity with regard to the temporality of the associations is avoided, and in addition recall bias is not likely to explain our findings, and there is also less possibility for selection bias. In addition, our meta-analysis included large cohort studies with relatively long follow-up and included 17,636 cases and 695471 participants in the BMI analysis, so we had statistical power to detect even moderate associations. The results were robust to the influence of single studies. The current findings have important public health implications as the prevalence of overweight and obesity has increased globally over the last decades [78], and this could contribute to an increased incidence of psoriasis as well as a range of other chronic diseases over time. In a recent Norwegian study approximately $25 \%$ of psoriasis cases could be attributed to overweight and obesity suggesting an important public health impact of excess weight on psoriasis risk [49].

In summary, our meta-analysis confirms a positive association between body fatness, waist circumference, waist-to-hip ratio, and weight gain and psoriasis risk. Any further studies should further assess the association between abdominal obesity and weight changes and psoriasis risk. Our findings confirm the previous recommendations to be as lean as possible within the normal BMI range and suggest that avoiding excess weight gain in adulthood may reduce the risk of psoriasis.

Acknowledgements The current project was funded by the Imperial College National Institute of Health Research (NIHR) Biomedical Research Centre (BRC). We thank Darren C. Greenwood (Biostatistics Unit, Centre for Epidemiology and Biostatistics, University of Leeds) for the Stata code for the nonlinear dose-response analysis.

Author's Contributions DA, IS, LJV conceived of the project. DA conducted the data extraction, study selection, statistical analyses and wrote the first draft of the manuscript. DA and SS conducted the screening of the literature search. All authors contributed to the revision of the manuscript. D. Aune takes responsibility for the integrity of the data and the accuracy of the data analysis.

\section{Compliance with ethical standards}

Conflict of interest The authors declare that there are no conflicts of interest.

Open Access This article is distributed under the terms of the Creative Commons Attribution 4.0 International License (http://creative commons.org/licenses/by/4.0/), which permits unrestricted use, distribution, and reproduction in any medium, provided you give appropriate credit to the original author(s) and the source, provide a link to the Creative Commons license, and indicate if changes were made.

\section{References}

1. Boehncke WH, Schon MP. Psoriasis. Lancet. 2015;386:983-94.

2. Danielsen K, Olsen AO, Wilsgaard T, Furberg AS. Is the prevalence of psoriasis increasing? A 30-year follow-up of a population-based cohort. Br J Dermatol. 2013;168:1303-10. 
3. Modalsli EH, Snekvik I, Asvold BO, Romundstad PR, Naldi L, Saunes M. Validity of self-reported psoriasis in a general population: the HUNT study, Norway. J Invest Dermatol. 2016;136:323-5.

4. Horreau C, Pouplard C, Brenaut E, et al. Cardiovascular morbidity and mortality in psoriasis and psoriatic arthritis: a systematic literature review. J Eur Acad Dermatol Venereol. 2013;27(Suppl 3):12-29.

5. Samarasekera EJ, Neilson JM, Warren RB, Parnham J, Smith CH. Incidence of cardiovascular disease in individuals with psoriasis: a systematic review and meta-analysis. J Invest Dermatol. 2013;133:2340-6.

6. Ahlehoff $\mathrm{O}$, Gislason $\mathrm{GH}$, Jorgensen $\mathrm{CH}$, et al. Psoriasis and risk of atrial fibrillation and ischaemic stroke: a Danish Nationwide Cohort Study. Eur Heart J. 2012;33:2054-64.

7. Ahlehoff O, Gislason G, Lamberts M, et al. Risk of thromboembolism and fatal stroke in patients with psoriasis and nonvalvular atrial fibrillation: a Danish nationwide cohort study. J Intern Med. 2015;277:447-55.

8. Pouplard C, Brenaut E, Horreau C, et al. Risk of cancer in psoriasis: a systematic review and meta-analysis of epidemiological studies. J Eur Acad Dermatol Venereol. 2013;27(Suppl 3):36-46.

9. Li WQ, Han JL, Chan AT, Qureshi AA. Psoriasis, psoriatic arthritis and increased risk of incident Crohn's disease in US women. Ann Rheum Dis. 2013;72:1200-5.

10. Ma C, Harskamp CT, Armstrong EJ, Armstrong AW. The association between psoriasis and dyslipidaemia: a systematic review. Br J Dermatol. 2013;168:486-95.

11. Armstrong AW, Harskamp CT, Armstrong EJ. The association between psoriasis and hypertension: a systematic review and meta-analysis of observational studies. J Hypertens. 2013;31:433-42.

12. Ungprasert $P$, Sanguankeo A, Upala S, Suksaranjit P. Psoriasis and risk of venous thromboembolism: a systematic review and meta-analysis. QJM. 2014;107:793-7.

13. Ungprasert P, Srivali N, Thongprayoon C. Association between psoriasis and chronic obstructive pulmonary disease: a systematic review and meta-analysis. J Dermatolog Treat. 2016;27:316-21.

14. Queiro R, Tejon P, Alonso S, Coto P. Age at disease onset: a key factor for understanding psoriatic disease. Rheumatology (Oxford). 2014;53:1178-85

15. Jankovic S, Raznatovic M, Marinkovic J, Jankovic J, Maksimovic N. Risk factors for psoriasis: a case-control study. J Dermatol. 2009;36:328-34.

16. Chen $\mathrm{H}$, Poon A, Yeung C, et al. A genetic risk score combining ten psoriasis risk loci improves disease prediction. PLoS ONE. 2011;6:e19454.

17. Huerta C, Rivero E, Rodriguez LA. Incidence and risk factors for psoriasis in the general population. Arch Dermatol. 2007;143:1559-65.

18. Tong LX, Wu S, Li T, Qureshi AA, Giovannucci EL, Cho E. Personal history of gallstones and risk of incident psoriasis and psoriatic arthritis in U.S. women. $\mathrm{Br} \mathbf{J}$ Dermatol. 2015;172:1316-22.

19. Armstrong AW, Harskamp CT, Dhillon JS, Armstrong EJ. Psoriasis and smoking: a systematic review and meta-analysis. $\mathrm{Br} \mathrm{J}$ Dermatol. 2014;170:304-14.

20. Brenaut E, Horreau C, Pouplard C, et al. Alcohol consumption and psoriasis: a systematic literature review. J Eur Acad Dermatol Venereol. 2013;27(Suppl 3):30-5.

21. Frankel HC, Han J, Li T, Qureshi AA. The association between physical activity and the risk of incident psoriasis. Arch Dermatol. 2012;148:918-24.

22. Wilson PB, Bohjanen KA, Ingraham SJ, Leon AS. Psoriasis and physical activity: a review. J Eur Acad Dermatol Venereol. 2012;26:1345-53.
23. Schon MP, Boehncke WH. Psoriasis. N Engl J Med. 2005;352:1899-912.

24. Hamminga EA, van der Lely AJ, Neumann HA, Thio HB. Chronic inflammation in psoriasis and obesity: implications for therapy. Med Hypotheses. 2006;67:768-73.

25. Cerman AA, Bozkurt S, Sav A, Tulunay A, Elbasi MO, Ergun T. Serum leptin levels, skin leptin and leptin receptor expression in psoriasis. Br J Dermatol. 2008;159:820-6.

26. Chen YJ, Wu CY, Shen JL, et al. Psoriasis independently associated with hyperleptinemia contributing to metabolic syndrome. Arch Dermatol. 2008;144:1571-5.

27. Oh YJ, Lim HK, Choi JH, Lee JW, Kim NI. Serum leptin and adiponectin levels in Korean patients with psoriasis. J Korean Med Sci. 2014;29:729-34.

28. Naldi L, Parazzini F, Peli L, Chatenoud L, Cainelli T. Dietary factors and the risk of psoriasis. Results of an Italian case-control study. Br J Dermatol. 1996;134:101-6.

29. Ozden MG, Tekin NS, Gurer MA, et al. Environmental risk factors in pediatric psoriasis: a multicenter case-control study. Pediatr Dermatol. 2011;28:306-12.

30. Huang YH, Yang LC, Hui RY, et al. Relationships between obesity and the clinical severity of psoriasis in Taiwan. J Eur Acad Dermatol Venereol. 2010;24:1035-9.

31. Paller AS, Mercy K, Kwasny MJ, et al. Association of pediatric psoriasis severity with excess and central adiposity: an international cross-sectional study. JAMA Dermatol. 2013;149:166-76.

32. Duarte GV, Oliveira MF, Cardoso TM, et al. Association between obesity measured by different parameters and severity of psoriasis. Int J Dermatol. 2013;52:177-81.

33. Jacobi A, Langenbruch A, Purwins S, Augustin M, Radtke MA. Prevalence of obesity in patients with psoriasis: results of the national study PsoHealth3. Dermatology. 2015;231:231-8.

34. Farshchian M, Ansar A, Sobhan M. Associations between cardiovascular risk factors and psoriasis in Iran. Clin Cosmet Investig Dermatol. 2015;8:437-42.

35. Lonnberg AS, Skov L, Skytthe A, Kyvik KO, Pedersen OB, Thomsen SF. Association of psoriasis with the risk for type 2 diabetes mellitus and obesity. JAMA Dermatol. 2016;152:761-7.

36. Naito R, Imafuku S. Distinguishing features of body mass index and psoriasis in men and women in Japan: a hospital-based casecontrol study. J Dermatol. 2016;43:1406-11.

37. Dellavalle RP, Johnson KR. Do smoking, obesity, and stress cause psoriasis? J Invest Dermatol. 2005;125:vi-vii.

38. Naldi L, Chatenoud L, Linder D, et al. Cigarette smoking, body mass index, and stressful life events as risk factors for psoriasis: results from an Italian case-control study. J Invest Dermatol. 2005;125:61-7.

39. Wolkenstein P, Revuz J, Roujeau JC, Bonnelye G, Grob JJ, Bastuji-Garin S. Psoriasis in France and associated risk factors: results of a case-control study based on a large community survey. Dermatology. 2009;218:103-9.

40. Wolk K, Mallbris L, Larsson P, Rosenblad A, Vingard E, Stahle M. Excessive body weight and smoking associates with a high risk of onset of plaque psoriasis. Acta Derm Venereol. 2009;89:492-7.

41. Zhang C, Zhu KJ, Zheng HF, et al. The effect of overweight and obesity on psoriasis patients in Chinese Han population: a hospital-based study. J Eur Acad Dermatol Venereol. 2011;25:87-91.

42. Johnson JA, Ma C, Kanada KN, Armstrong AW. Diet and nutrition in psoriasis: analysis of the National Health and Nutrition Examination Survey (NHANES) in the United States. J Eur Acad Dermatol Venereol. 2014;28:327-32.

43. Armstrong AW, Harskamp CT, Armstrong EJ. The association between psoriasis and obesity: a systematic review and metaanalysis of observational studies. Nutr Diabetes. 2012;2:e54. 
44. Setty AR, Curhan G, Choi HK. Obesity, waist circumference, weight change, and the risk of psoriasis in women: nurses' Health Study II. Arch Intern Med. 2007;167:1670-5.

45. Kumar S, Han J, Li T, Qureshi AA. Obesity, waist circumference, weight change and the risk of psoriasis in US women. J Eur Acad Dermatol Venereol. 2013;27:1293-8.

46. Harpsoe MC, Basit S, Andersson M, et al. Body mass index and risk of autoimmune diseases: a study within the Danish National Birth Cohort. Int J Epidemiol. 2014;43:843-55.

47. Danielsen K, Wilsgaard T, Olsen AO, Furberg AS. Overweight and weight gain predict psoriasis development in a populationbased cohort. Acta Derm Venereol. 2016;97:332-9.

48. Kim ES, Han K, Kim MK, et al. Impact of metabolic status on the incidence of psoriasis: a Korean nationwide cohort study. Sci Rep. 2017;7:1989.

49. Snekvik I, Smith CH, Nilsen TIL, et al. Obesity, waist circumference, weight change and risk of incident psoriasis: prospective data from the HUNT Study. J Invest Dermatol. 2017;137:2484-90.

50. Janssen I, Katzmarzyk PT, Ross R. Body mass index, waist circumference, and health risk: evidence in support of current National Institutes of Health guidelines. Arch Intern Med. 2002;162:2074-9.

51. Lee CMY, Woodward M, Pandeya N, et al. Comparison of relationships between four common anthropometric measures and incident diabetes. Diabetes Res Clin Pract. 2017;132:36-44.

52. Stroup DF, Berlin JA, Morton SC, et al. Meta-analysis of observational studies in epidemiology: a proposal for reporting. Meta-analysis Of Observational Studies in Epidemiology (MOOSE) group. JAMA. 2000;283:2008-12.

53. Aune D, Greenwood DC, Chan DS, et al. Body mass index, abdominal fatness and pancreatic cancer risk: a systematic review and non-linear dose-response meta-analysis of prospective studies. Ann Oncol. 2012;23:843-52.

54. Aune D, Navarro Rosenblatt DA, Chan DS, et al. Anthropometric factors and endometrial cancer risk: a systematic review and dose-response meta-analysis of prospective studies. Ann Oncol. 2015;26:1635-48.

55. DerSimonian R, Laird N. Meta-analysis in clinical trials. Control Clin Trials. 1986;7:177-88.

56. Greenland S, Longnecker MP. Methods for trend estimation from summarized dose-response data, with applications to meta-analysis. Am J Epidemiol. 1992;135:1301-9.

57. Hamling J, Lee P, Weitkunat R, Ambuhl M. Facilitating metaanalyses by deriving relative effect and precision estimates for alternative comparisons from a set of estimates presented by exposure level or disease category. Stat Med. 2008;27:954-70.

58. Bagnardi V, Zambon A, Quatto P, Corrao G. Flexible meta-regression functions for modeling aggregate dose-response data, with an application to alcohol and mortality. Am J Epidemiol. 2004;159:1077-86.

59. Wells G, Shea B, O'Connell D. et al. The Newcastle-Ottawa Scale (NOS) for assessing the quality of nonrandomised studies in meta-analyses. http://www.ohri.ca/programs/clinical_epide miology/oxford.asp. Accessed 01 Aug 2017.

60. Higgins JP, Thompson SG. Quantifying heterogeneity in a metaanalysis. Stat Med. 2002;21:1539-58.

61. Egger M, Davey SG, Schneider M, Minder C. Bias in metaanalysis detected by a simple, graphical test. BMJ. 1997;315:629-34.
62. Begg CB, Mazumdar M. Operating characteristics of a rank correlation test for publication bias. Biometrics. 1994;50:1088-101.

63. Li RC, Krishnamoorthy P, DerOhannessian S, et al. Psoriasis is associated with decreased plasma adiponectin levels independently of cardiometabolic risk factors. Clin Exp Dermatol. 2014;39:19-24.

64. Stjernholm T, Ommen P, Langkilde A, et al. Leptin deficiency in mice counteracts imiquimod (IMQ)-induced psoriasis-like skin inflammation while leptin stimulation induces inflammation in human keratinocytes. Exp Dermatol. 2017;26:338-45.

65. de Menezes Ettinger JE, Azaro E, de Souza CA, et al. Remission of psoriasis after open gastric bypass. Obes Surg. 2006;16:94-7.

66. Perez-Perez L, Allegue F, Caeiro JL, Zulaica JM. Severe psoriasis, morbid obesity and bariatric surgery. Clin Exp Dermatol. 2009;34:e421-2.

67. Hossler EW, Maroon MS, Mowad CM. Gastric bypass surgery improves psoriasis. J Am Acad Dermatol. 2011;65:198-200.

68. Faurschou A, Zachariae C, Skov L, Vilsboll T, Knop FK. Gastric bypass surgery: improving psoriasis through a GLP-1-dependent mechanism? Med Hypotheses. 2011;77:1098-101.

69. Farias MM, Achurra P, Boza C, Vega A, de la Cruz C. Psoriasis following bariatric surgery: clinical evolution and impact on quality of life on 10 patients. Obes Surg. 2012;22:877-80.

70. Romero-Talamas H, Aminian A, Corcelles R, Fernandez AP, Schauer PR, Brethauer S. Psoriasis improvement after bariatric surgery. Surg Obes Relat Dis. 2014;10:1155-9.

71. Yildiz BD. Rapid remission of psoriasis after sleeve gastrectomy. Indian J Surg. 2016;78:60-2.

72. Jensen P, Zachariae C, Christensen R, et al. Effect of weight loss on the severity of psoriasis: a randomized clinical study. JAMA Dermatol. 2013;149:795-801.

73. Jensen P, Christensen R, Zachariae C, et al. Long-term effects of weight reduction on the severity of psoriasis in a cohort derived from a randomized trial: a prospective observational follow-up study. Am J Clin Nutr. 2016;104:259-65.

74. Upala S, Sanguankeo A. Effect of lifestyle weight loss intervention on disease severity in patients with psoriasis: a systematic review and meta-analysis. Int J Obes (Lond). 2015;39:1197-202.

75. Bruun JM, Helge JW, Richelsen B, Stallknecht B. Diet and exercise reduce low-grade inflammation and macrophage infiltration in adipose tissue but not in skeletal muscle in severely obese subjects. Am $\mathrm{J}$ Physiol Endocrinol Metab. 2006;290:E961-7.

76. Rimm EB, Stampfer MJ, Colditz GA, Chute CG, Litin LB, Willett WC. Validity of self-reported waist and hip circumferences in men and women. Epidemiology. 1990;1:466-73.

77. Wright FL, Green J, Reeves G, Beral V, Cairns BJ. Validity over time of self-reported anthropometric variables during follow-up of a large cohort of UK women. BMC Med Res Methodol. 2015; $15: 81$.

78. NCD Risk Factor Collaboration. Trends in adult body-mass index in 200 countries from 1975 to 2014: a pooled analysis of 1698 population-based measurement studies with 19.2 million participants. Lancet. 2016;387:1377-96. 